\section{Asking sensitive questions in conservation using the Unmatched Count Technique}

\section{What is UCT?}

The Unmatched Count Technique (UCT), or list experiment, is an indirect questioning technique which allows answers to remain confidential and respondents to be protected. Because questions are asked in an indirect way, it is used to inquire about illegal activities or behaviours people might not want to openly admit to. The method provides an estimate of how many people within a population are performing the behaviour in question. Its indirect nature should produce more truthful answers than directly asking respondents whether they have engaged in an illegal or sensitive activity, thus providing a more reliable estimate of prevalence of people performing the behaviour. Although using UCT will not uncover why people are performing a given behaviour, its analysis can produce results to indicate which characteristics (e.g. location, gender, age, income) of the population surveyed are more likely to affect whether a person is engaging in the behaviour.

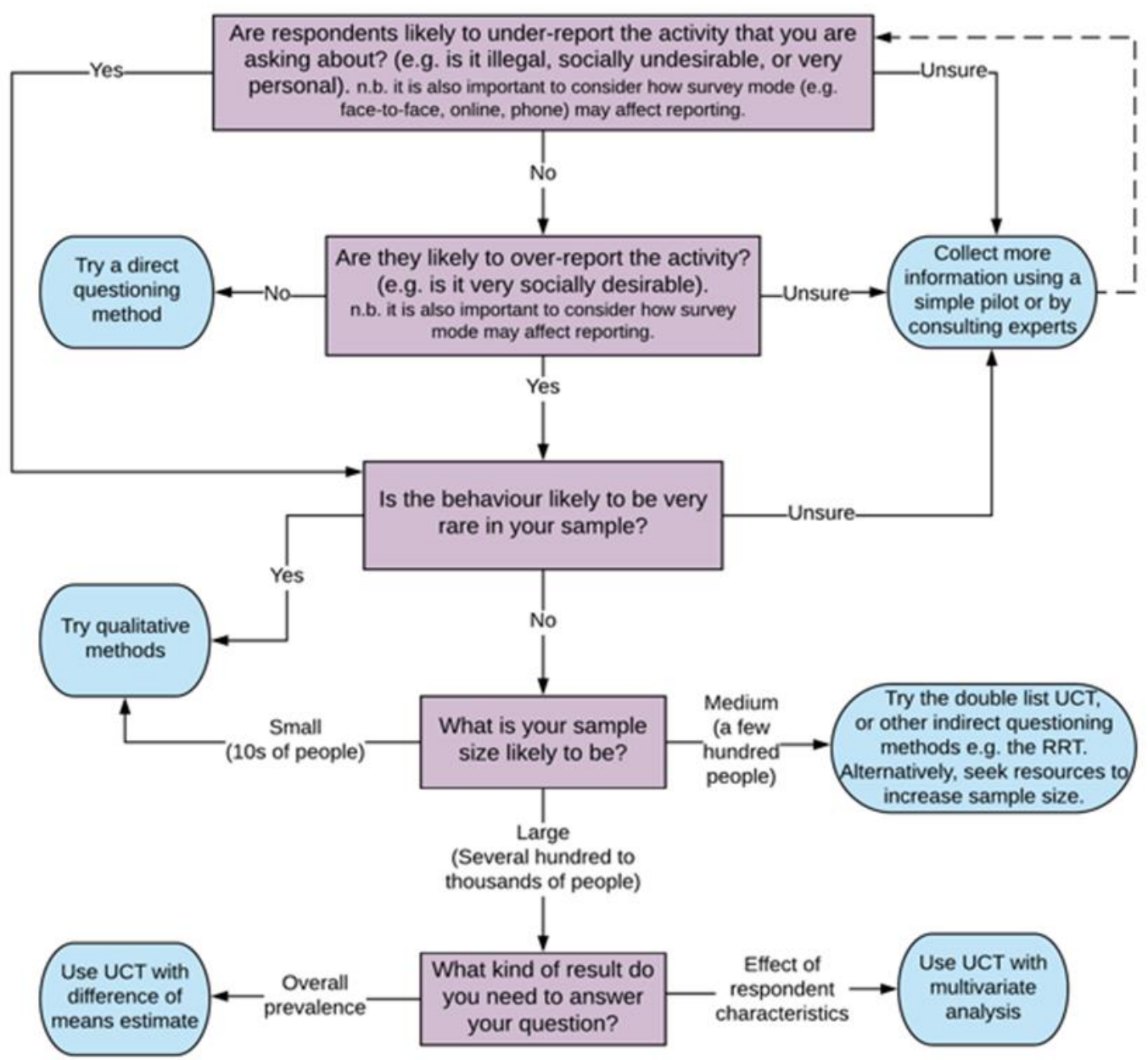

Fig 1. Decision tree to assess the suitability of UCT, and when other methods may be more appropriate (Hinsley et al. 2018) 
There are several things to consider before deciding if UCT is the most appropriate research method; if its design and implementation is not adequate, it might not work at all. Firstly, there are logistical considerations: sample size (which relies on funding and time) and having the human resources and time to pilot the questions before starting data collection. The sample size will vary between studies, depending on how prevalent the behaviour in question is; if it is rare amongst the population, the study will require a larger sample size. Number of respondents of UCT surveys have ranged from 50 to over 20,000 - but the majority have used around 1,000 respondents. Other considerations must be thought of once the research question has been formulated. The diagram on page 1 (Fig. 1), developed by Hinsley et al. (2018), can help guide the decision on whether UCT should be used.

\section{How does it work?}

The UCT presents a sensitive behaviour of interest among a list of other related (but non-sensitive) 'control' items. First, respondents are randomly divided into two groups, which can be done using randomisation functions in survey software if an online/tablet survey is used, or with a simple randomisation method such as a coin toss or random number generator. For cases where randomisation in the field is challenging, researchers can use the ABBA method; where, if the block size is four, the first respondent $(A)$ is assigned to the control or treatment group, the next two respondents (BB) are assigned to the other group and the following respondent $(A)$ is assigned to the first group. With randomisation or the ABBA method, half of respondents are shown a list of control items,

and the other half is presented the same list with an additional sensitive item. Examples 1 (Hinsley et al. 2018) and 2 show two real UCT lists that have been used in the field to ask about illegal orchid trade and pangolin meat consumption respectively. In these examples, the blue shading denotes nonsensitive 'control' items, and yellow shading is used for the sensitive behaviour in question. Whilst these lists contain only text, a UCT can also include drawings to make it more appealing and easier to understand, especially where literacy levels are low.

\section{EXAMPLE 1}

Please read the following statements and tell us how many are true for you. You do not need to tell us which statements are true for you, just the total number.

\begin{tabular}{|c|}
\hline Control Group \\
\hline $\begin{array}{c}\text { I have never bought orchids at an } \\
\text { orchid show }\end{array}$ \\
\hline $\begin{array}{c}\text { I am a member of a Facebook } \\
\text { orchid group }\end{array}$ \\
\hline I have a species [orchid] collection \\
\hline $\begin{array}{c}\text { I have been a member of an orchid } \\
\text { society for more than a year }\end{array}$ \\
\hline
\end{tabular}

\section{EXAMPLE 2}

Please read the list below. How many of the items below have you consumed in the last 12 months (present month included)? The products you do not count are those you have not consumed even once in the last 12 months.

\begin{tabular}{|c|}
\hline Control Group \\
\hline Snails \\
\hline Squid \\
\hline Crocodile meat \\
\hline Hu tieu \\
\hline
\end{tabular}

\begin{tabular}{|c|}
\hline Treatment Group \\
\hline Snails \\
\hline Squid \\
\hline Pangolin meat \\
\hline Crocodile meat \\
\hline Hu tieu \\
\hline
\end{tabular}

Respondents are shown the list and asked to state the total number of items that apply to them. As demonstrated by these examples, depending on the question being asked, the answer could be how many of the items they have bought or consumed, how many of the activities they have done, or how many 
statements they agree with. It is important that they give the total number, and do not state which specific items apply to them so that respondents are not directly asked about performing the behaviour in question.

To obtain the prevalence for the presence of the sensitive behaviour, the mean answer for each group is calculated, and the control group mean subtracted from the treatment group mean to give the proportion of people who have said yes to the sensitive item. To illustrate this with Example 2, if the mean answer for the control group was 2.6, and the mean for the treatment was 2.8 , then the difference would be 0.2 , suggesting that the proportion of people who had consumed pangolin meat in the last 12 months is $20 \%$.

\section{How to design a control list?}

The UCT is only useful if it is designed well, and it should not be used if the time or resources available are not adequate to do this. The most important task is putting together a list of control items and this requires a lot of thought, trial and, potentially, error. A pilot survey can be used to determine whether control items meet certain criteria, and this should test several potential control items at once (at least 10) with the survey target audience. The pilot should focus on the following issues to ensure that the control items are:

\section{- Relevant}

Control items must be somewhat related to the sensitive item and should be phrased in a similar way, so the sensitive item does not stand out. The control item should also be relevant to the reality of the situation and ideally not obviously impossible.

\section{- Non-sensitive}

In the basic UCT design, only one sensitive item is used, so control items should be checked to ensure that they themselves are not sensitive for any reason. This can be determined by how willing people are to talk about/admit to the behaviour.

\section{- Unambiguous}

Whether items are a statement or a single word, they must be very clear, to ensure that respondents recognise the item, are not confused and know right away if it applies to them or not. Multiple interpretations of an item should also be checked for.

\section{- Not all too rare or common}

Ideally, each list should include some items that apply to most people (high prevalence), some that only apply to about half (medium prevalence) and some that only apply to very few people (low prevalence). Although familiarity with the study population helps with the design, it is still better to test the prevalence of control items to ensure there is the right mix in each list.

CASE-STUDY. The draft control item list for Example 2 (page 2) originally included 'international cuisine' and 'Lotteria' (restaurant chain in Vietnam) as control items. Testing these with respondents in Vietnam revealed 'international cuisine' was understood both as fast food, such as pizza and burgers which are common among young people and somewhat cheap, and as high-end French, Italian or Japanese cuisine served at expensive restaurants. This item was thus not included as it was confusing for respondents due to its multiple interpretations. 'Lotteria' was removed as the sensitive item is a single food item while 'Lotteria' is a restaurant, so these cannot be included in the same category. 
Once tested, any items that do not meet these criteria should be removed, and the final control list selected. The number of control items varies between studies, but four items is common, as in the examples above. It has been argued that it is harder for respondents to keep count when the items number presented is high and adding more will increase the error of the results.

\section{Piloting a UCT}

When the control items have been tested, the next step is to pilot both control and treatment questions with respondents from the same audience with which the final survey will be conducted. This helps to confirm that the survey is appropriate and understandable for the respondents and ensures that surveyors become comfortable with administering the questionnaire and explaining how UCT questions must be answered. An example UCT question can be used to familiarise respondents with the method without a sensitive item being present. For example, a control list of simple items (e.g. 'Which of these fruits have you eaten?'), and a treatment list containing one extra (but non-sensitive) item.

Piloting will help identify if there are issues with the design of control and treatment lists. The table on the right covers some potential issues and steps that can be taken to address these.

\section{Analysing a UCT}

\section{- Design effect}

The R package, 'list', has been designed specifically for UCT analysis. The first test detects if there is a design effect. This means that the presence of the sensitive item in the treatment list is affecting the answers the respondents give for the control items. If a design effect is found then the prevalence estimate will not be accurate, and further analysis should not be carried out.

\begin{tabular}{|c|c|}
\hline Issue & What can be done? \\
\hline $\begin{array}{l}\text { Majority of } \\
\text { respondents' } \\
\text { answers show } \\
\text { none or just } 1 \\
\text { of the items } \\
\text { apply to them. }\end{array}$ & $\begin{array}{l}\text { Control items should be } \\
\text { revised, some with higher } \\
\text { prevalence included. }\end{array}$ \\
\hline $\begin{array}{l}\text { Majority of } \\
\text { respondents' } \\
\text { answers show } \\
\text { all the items } \\
\text { apply to them. }\end{array}$ & $\begin{array}{l}\text { Control items should be } \\
\text { revised, some with lower } \\
\text { prevalence included. }\end{array}$ \\
\hline $\begin{array}{l}\text { Respondents } \\
\text { are } \\
\text { underreporting } \\
\text { their answers. } \\
\text { Note that UCT } \\
\text { is known to } \\
\text { result in slight } \\
\text { underreporting } \\
\text { compared to } \\
\text { direct } \\
\text { questions, but } \\
\text { this can be } \\
\text { mitigated to } \\
\text { some extent. }\end{array}$ & $\begin{array}{l}\text { - Direct questions on each } \\
\text { of the control items can } \\
\text { be added at the end of the } \\
\text { survey. Can be a simple } \\
\text { 'Have you done the } \\
\text { following behaviour?' with } \\
\text { a 'Yes'or 'No'answer. } \\
\text { Direct question answers } \\
\text { can be compared with } \\
\text { those of the UCT to } \\
\text { determine whether the } \\
\text { prevalence of control } \\
\text { items is indeed low. These } \\
\text { direct questions should be } \\
\text { asked of all respondents in } \\
\text { both control and } \\
\text { treatment groups. } \\
\text { - List of control items might } \\
\text { be too long. } \\
\text { - If underreporting is only } \\
\text { taking place in the } \\
\text { treatment group, then the } \\
\text { sensitive item may be } \\
\text { making people } \\
\text { uncomfortable. This could } \\
\text { be addressed by } \\
\text { reiterating anonymity } \\
\text { before the UCT question. } \\
\text { If the level of } \\
\text { underreporting is the } \\
\text { same for both control and } \\
\text { treatment groups, the } \\
\text { difference in means } \\
\text { between the two groups } \\
\text { should not be drastically } \\
\text { affected. }\end{array}$ \\
\hline
\end{tabular}


- $\quad$ Difference in means

The difference in means test is used to estimate the prevalence of the sensitive behaviour and can also be carried out with the 'list' package. If UCT has worked well, and there is no design effect, then the difference in means between treatment and control questions should be positive. Additionally, the test will provide standard errors; the smaller the standard error the more confident researchers can be in the estimate of prevalence. Sometimes the standard error overlaps with zero, suggesting a negative prevalence, which is of course impossible. In this case, the prevalence of the sensitive behaviour cannot be calculated as there is no evidence for the presence of the behaviour.

- Multivariate analysis

The 'list' package also allows a multivariate analysis to be conducted, which can reveal what types of respondents are more likely to perform the behaviour in question relative to each other. For example, lower income respondents are more likely to consume pangolin meat than higher income respondents. To decide which variables (e.g. income, gender, location, age) can be in the same model, variables must be tested for collinearity. Variables that have collinearity with each other are those that have an effect on each other already (such as age and income; it would be expected that older people fall in a higher income category than young people). Collinear variables should not be included in the same model. Alternatively, a normal generalized linear model (GLM) can be conducted using all variables, and model averaging (e.g. using the $R$ package 'MuMIn') used to select a final model.
Summary checklist

UCT requires careful thought and critical reflection through the design process. Use this checklist to make sure you have:

$\checkmark$ Checked that it is the best method for your study;

$\checkmark$ Expertise on the study population, or are collaborating with somebody who has;

$\checkmark$ Chosen and tested your control statements;

$\checkmark \quad$ Piloted your final UCT to ensure respondents understand and trust it;

$\checkmark$ Checked for recent developments in analysis techniques and chosen the most appropriate one for your question.

\section{Key references}

Blair G. \& Imai K. 2012. Statistical Analysis of List Experiments. Polit Anal. 20.

Glynn A. N. 2010. What Can We Learn with Statistical Truth Serum? Design and Analysis of the List Experiment. Public Opin Q. 77.

Hinsley et al. 2018. Asking sensitive questions using the unmatched count technique: Applications and guidelines for conservation. Methods Ecol Evol. 10(3).

Tsuchiya T. \& Hirai Y. 2010. Elaborate Item Count Questioning: Why Do People Underreport in Item Count Responses? Surv. Res. Methods. 4(3).

\section{Suggested Citation}

Olmedo A., Davis E., Hinsley A. 2019. Asking sensitive questions in conservation using the Unmatched Count Technique. Tools and Guidance, Oxford Martin Programme on the Illegal Wildlife Trade, University of Oxford. DOI: 10.31235/osf.io/rcdbk 